\title{
Design of a test bench to characterize mechanical phenomena involved in a bolted joint
}

\author{
Yongsheng Zhao ${ }^{1, a)}$, Weikai $\mathrm{Li}^{1, \mathrm{~b})}$, Weizhe $\mathrm{Yu}^{1, \mathrm{c})}$ \\ ${ }^{1}$ College of Mechanical Engineering and Applied Electronics Technology, \\ Beijing University of Technology, Beijing 100124, China. \\ a)yszhao@bjut.edu.cn, ${ }^{\text {b) }} 770441906 @ q q . c o m,{ }^{\text {c) }} 529478363 @ q q . c o m$
}

Keywords: Test bench, Bolted joint, Characterize mechanical phenomena

\begin{abstract}
Parts of assembly are mainly fixed and connected by bolts. The performance of the assembly can be affected by the dynamic characteristics of the bolted joints. Report focuses on designing a test bench by parameter analysis and achieving the dynamic analysis of the bolted joint. In the first part, the eigenfrequency of a simple single beam with different size parameters are analyzed with NASTRAN and the complex model of the bolted joint are analyzed. After that the effects of different parameters on the eigenfrequency are obtained and a bolted joint test bench is designed with CATIA. In the second part, a model specimen is made. The material of bolts is changed to compare the dynamic response with different preloads using Polytec Scanning Vibrometer. At last, the comparisons between experimental results and numerical simulation are obtained.
\end{abstract}

\section{INTRODUCTION}

Bolted joints are still the dominant fastening mechanism used in joining of primary structural parts for metallic structures. Many companies from many industrial fields focus on lightweight constructions in order to save weight and energy. The complex behavior of connecting elements plays an important role in the overall dynamic characteristics, such as natural frequencies, mode shapes, and non-linear response characteristics to external excitations. The joint represents a discontinuity in the structure and results in high stresses that often initiate joint failure [1]. Design and test techniques relating to the static strength and to the gross dynamic responses of such structures are highly developed and have long been used throughout the aircraft industry [2]. To mount an assembly (assembly = bolt + washer + nut), it is essential to apply adequate tightening torque. This torque creates tension in the bolt which keeps the elements in contact. There are some studies about influence of tightening torque on the global behavior and on the failure mode of the bolted joint [3]. Mechanical joints can have a significant effect on the dynamics of structures that contain them. Accurate prediction of dynamic response of assembled structures to external excitation often hinges on efficacious modelling of the effect of the joint on structural behavior [4]. The stresses and slip in the vicinity of contact regions determine the static strength, cyclic plasticity, frictional damping, and vibration levels associated with the structure. The need for developing methodologies for constructing predictive models of structures with joints and interfaces has recently been discussed in a white paper by Dohner [5]. In view of joint uncertainties and relaxation, energy dissipation is one of the prime factors in the value of transmitting loads from one structural element to the next connected element. The treatment of joint uncertainties may be described using the theory of fuzzy sets, which will be briefly defined and demonstrated by some examples. The dynamic analysis of non-linear structures with joint relaxation will be presented for random and sinusoidal excitations. The article will address the identification problem of linear and non-linear joints $[6,7,8]$. In view of joint uncertainties and relaxation, energy dissipation is one of the prime factors in the value of transmitting loads from one structural element to the next connected element. Basic considerations in the design of joints of composite structures are discussed by Agarwal and Broutman [9]. Kuanmin [10] researched the stiffness influential factors-based dynamic modeling and its parameter identification method of fixed joints in machine tools. Y. Song [4] presents an 
adjusted Iwan beam element (AIBE) for dynamic response analysis of beam structures containing joints. The adjusted Iwan model consists of a combination of springs and frictional sliders that exhibits non-linear behavior due to the stick-slip characteristic of the latter. Yongsheng Zhao [11] presents a non-linear virtual material method based on surface contact stress to describe the bolted joint for accurate dynamic performance analysis of the bolted assembly. Fractal geometry theory is used to describe the surface topography and fractal contact theory can derive the elastic modulus and shear modulus of one micro-contact.

The aim of thesis is to design a test bench bolted joint allowing to highlight the main physical phenomena operating at the joint level and having an impact on the vibrational behavior of a given bolted structure. Depending on the parameters of the model and the software simulation, a bolted joint test bench will be designed. Then the characteristics of the bolted joint will be analyzed, especially the dynamic analysis. The material and preload of the bolt will be changed to compare the different dynamic response.

\section{THE DESIGN PROCESS OF A TEST BENCH}

\section{Characteristics of the simple beam}

In this section, the flexural vibrations of a simple single beam with different size parameters are analyzed. Through the different parameter values, the regular pattern between eigenfrequency and parameter can be obtained. There is a straight beam of second moment of area with respect to y-axis. The size parameters are: $\mathbf{L}$ the length, $\mathbf{b}$ the width and $\mathbf{h}$ the thickness. The material properties of the beam are: $\mathbf{E}$ the Young's modulus, $\boldsymbol{v}$ the Poisson ratio, and $\boldsymbol{\rho}$ the density (Fig. 1).

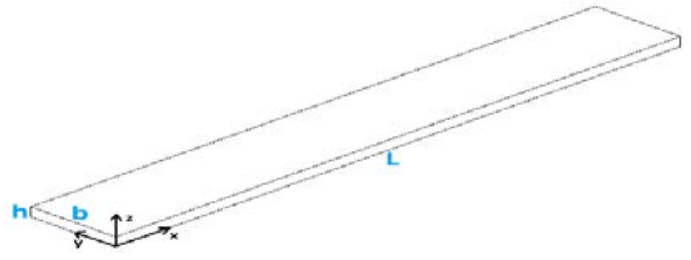

FIGURE 1. Simple beam.

The natural frequencies $\mathrm{f}_{\mathrm{k}}=\frac{\omega_{\mathrm{k}}}{2 \pi}$ (where $\omega_{\mathrm{k}}$ is the natural pulsation) and mode shape $\phi_{\mathrm{k}}$ of this beam in bending is solutions of:

$$
E I_{\mathrm{y}} \phi_{\mathrm{k}}^{\prime \prime \prime}(\mathrm{x})-\rho S \omega_{\mathrm{k}}^{2} \phi_{\mathrm{k}}(\mathrm{x})=0
$$

The natural pulsation of equation (1) is computed from:

Simplification (2):

$$
\omega_{\mathrm{k}}=\left(\beta_{\mathrm{k}} \mathrm{L}\right)^{2} \sqrt{\frac{\mathrm{ET}_{\mathrm{y}}}{\mathrm{\rho SL}^{4}}} \text { with: } \mathrm{I}_{\mathrm{y}}=\frac{\mathrm{bh}^{3}}{12}
$$

$$
\omega_{\mathrm{k}}=\left(\beta_{\mathrm{k}} \mathrm{L}\right)^{2} \sqrt{\frac{\mathrm{E}}{12 \rho}} \mathbf{a} \text { with: } \mathbf{a}=\frac{\mathrm{h}}{\mathrm{L}^{2}}
$$

The configuration is free-free.

So $\cos \left(\beta_{k} L\right) \cosh \left(\beta_{k} L\right)=1, \beta_{0} L=0$ (rigid body mode), $\beta_{1} L=4.7300, \beta_{2} L=7.8532, \beta_{3} L=10.9956$, $\beta_{4} \mathrm{~L}=14.1372, \beta_{5} \mathrm{~L}=17.2787$. 


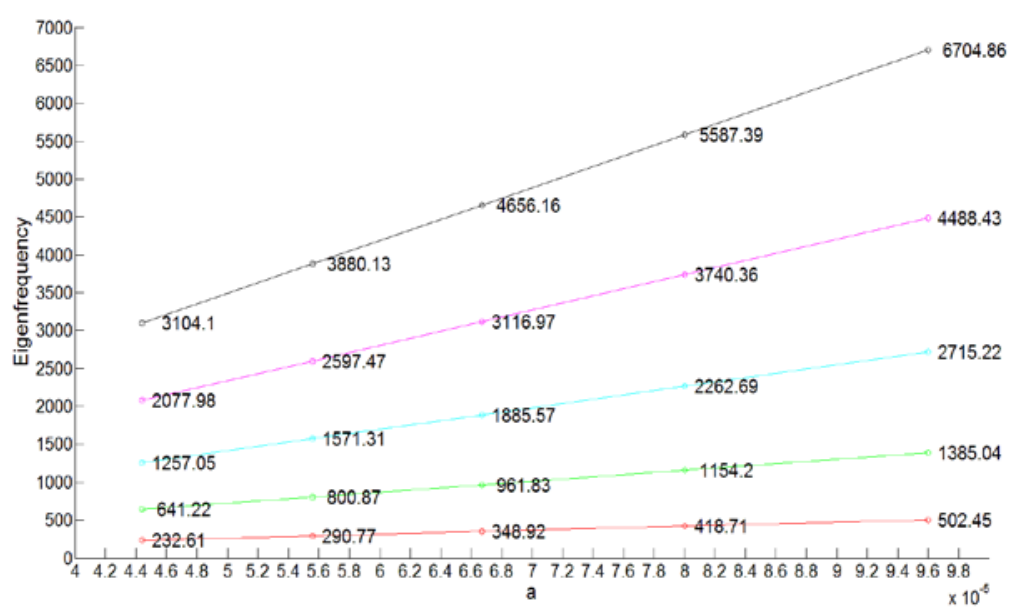

FIGURE 2. Eigenfrequency in all case.

By changing the shapes of different sizes, the different data about the flexural vibrations of beam are obtained. The eigenfrequency exhibits a linear shape increase with the increase of the parameter. From the total figure (Fig. 2), the appropriate dimension of beam can be determined by a given frequency range.

\section{Characteristics of the bolted joint model}

After analysis of simple beam, a complex model of the bolted joint is analyzed. When ignoring the relative movement and friction between the joint surfaces, the dynamic characteristics of the single unitary model are similar with the assembly model. In this section, the different dynamic simulations for different parameters are made. At last the effects of different parameters on the eigenfrequency are obtained.

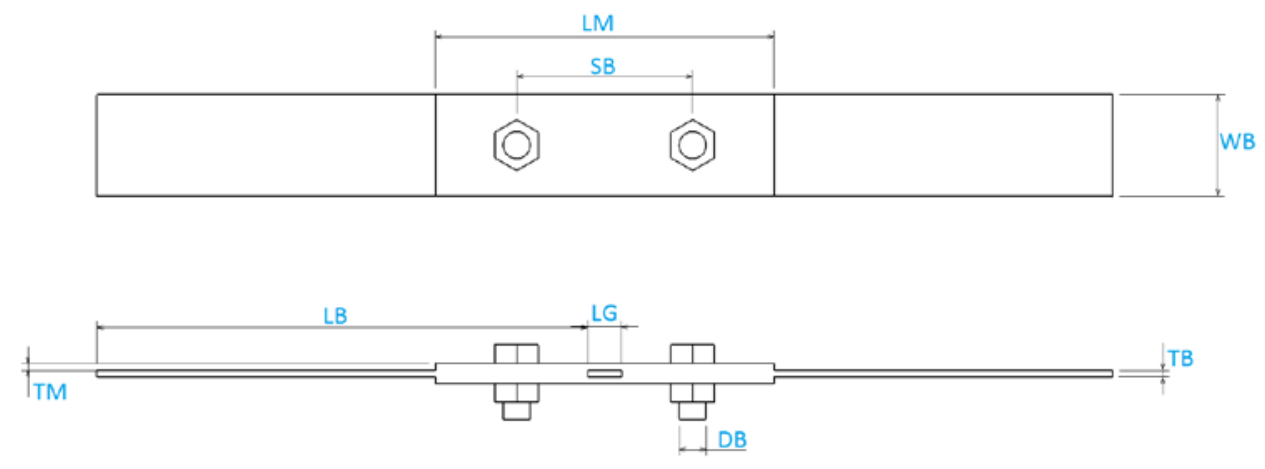

FIGURE 3. Model simple diagram.

There are some valid parameters in the model (Fig. 3). The length of the beam (LB) is fixed, the value is $140 \mathrm{~mm}$. Parameter 1 (LM): The length of middle portion. Parameter 2 (LG): The length of gap. Parameter 3 (TM): The thickness of middle portion. Parameter 4 (TB): The thickness of beam. Parameter 5 (WB): The width of beam. Parameter 6 (DB): The diameter of bolt. Parameter 7 (SB): The space of bolts.

When ignoring the relative movement and friction between the joint surfaces, the dynamic characteristics of the single unitary model are similar with the assembly model. The different dynamic simulations for different parameters are made with CATIA. By changing the different parameters, we can get different results. For each parameter, I make it float up and down ten percent and obtain the different influence coefficient (Table 1). From the table we can find that the thickness of beam (TB) and the length of middle portion (LM) make the maximum impact on the model's eigenfrequency and the diameter of bolt (DB) makes the minimal impact factor. 
TABLE 1. The sequence of parameter's effect.

\begin{tabular}{|c|c|c|}
\hline Sequence & Parameter & Value \\
\hline 1 & The thickness of beam (TB) & $5.81 \%$ \\
\hline 2 & $\begin{array}{c}\text { The length of middle portion } \\
\text { (LM) }\end{array}$ & $3.46 \%$ \\
\hline 3 & The width of beam (WB) & $0.78 \%$ \\
\hline 4 & The length of gap (LG) & $0.77 \%$ \\
\hline 5 & The thickness of middle portion & $0.57 \%$ \\
\hline 6 & The & $0.09 \%$ \\
\hline 7 & The diameter of bolt (DB) & $0.07 \%$ \\
\hline
\end{tabular}

When ignoring the relative movement and friction between the joint surfaces, the dynamic characteristics of the single unitary model are similar with the assembly model. So a single unitary model instead of the actual specimen can be used. Geometry model is shown on Fig. 4 with CATIA.

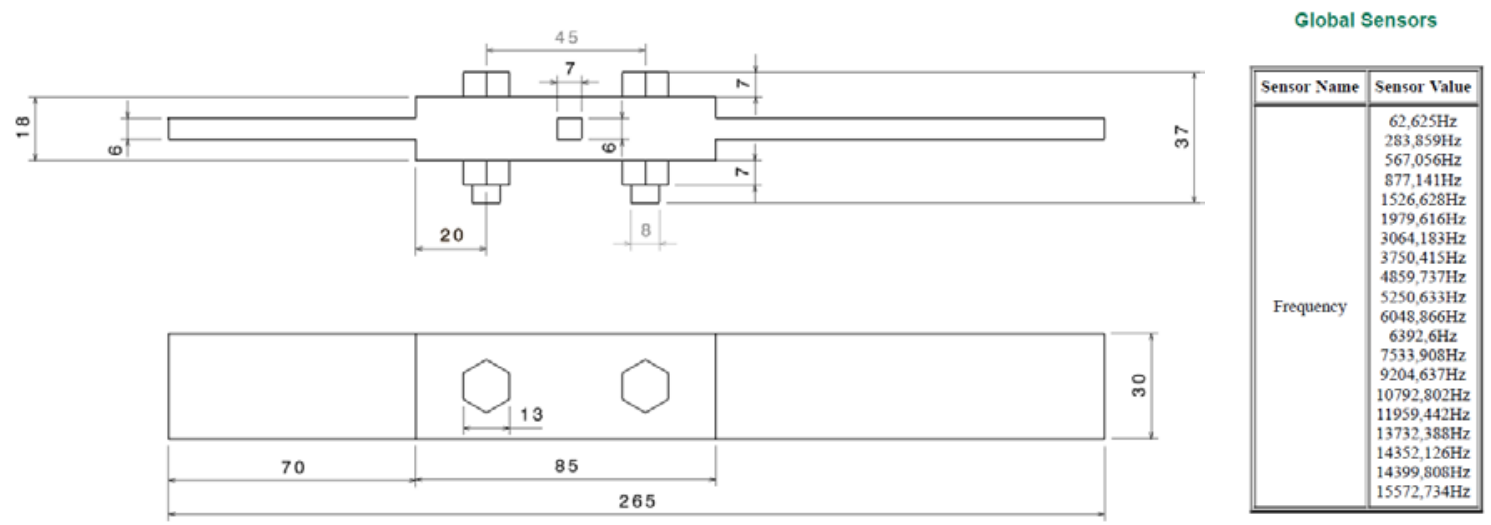

FIGURE 4. Single unitary model size and eigenfrequency.

It is summarized that the thickness of beam makes the maximum impact on the model's eigenfrequency and the diameter of bolt makes the minimal impact factor. Through this analysis, the geometry can't be directly determined. But reasonable range of size can be determined by eigenfrequency. If the frequency of the dynamic response is more than $2000 \mathrm{~Hz}$, the instrument can only measure. For the simulation model, the first four eigenfrequencies are less than $2000 \mathrm{~Hz}$, so this size of the model is feasible for the experiment.

\section{DYNAMIC ANALYSIS OF THE BOLTED JOINT}

In the experiment, there are two parts to measure dynamic response under different preloads. Laboratory equipment contains strain gauge and Polytec Scanning Vibrometer. First, the strain gauge is inside the bolt and the bolt material is aluminum. Second, the material of bolt is changed to steel. By changing different preloads, the results of different experiments can be compared.

\section{Aluminum bolt experiment}

In this part, in order to compare the experimental data, a software simulation and the local preload analysis are made. Then the specimen experiment of the bolted joint is made. To obtain more accurate results, two sets of experiments are conducted and the eigenfrequencies with different preloads are compared.

The geometry of experimental model is as follow (Fig. 5). Only the nut and washer are steel, others are all aluminum. The mesh type is OCTREE Tetrahedron Mesh. Because the minimum thickness of the specimen is very small, in order to obtain accurate results, the size of mesh is selected a smaller value which is $1 \mathrm{~mm}$. The number of nodes is 74679 and the number of elements is 312984 . 

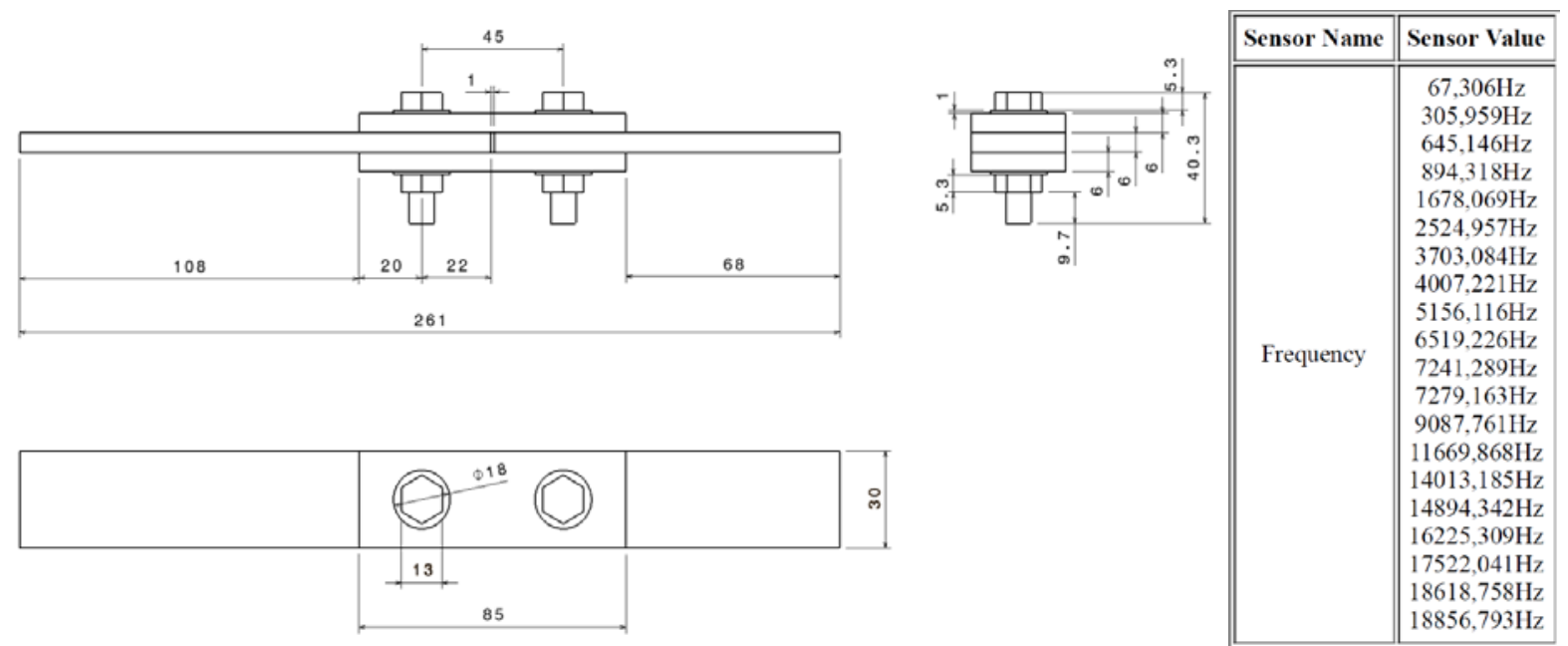

FIGURE 5. Specimen size and eigenfrequency.

In order to obtain the preload of every bolt, aluminum bolts are used and each bolt has an axial strain gauge (Fig. 6). Gauge length is $3 \mathrm{~mm}$, gauge resist is $120 \pm 0.3 \Omega$ and gauge factor is 2.14 . Strain values for each bolt can be measured by strain gauge and the internal preload can be calculated. The screw section area $\mathrm{A}_{\text {screw }}$ and the elastic modulus $\mathrm{E}_{\text {bolt }}$. It can be measured the axial compressive strain value $\epsilon_{\text {axial }}$ with the strain gauge. The axial stress $\sigma_{\text {axial }}$ is obtained by:

$F_{\text {axial }}$ is the axial applied load:

$$
\sigma_{\text {axial }}=\mathrm{E}_{\text {bolt }} \cdot \epsilon_{\text {axial }}
$$

$$
\mathrm{F}_{\text {axial }}=\sigma_{\text {axial }} \cdot \mathrm{A}_{\text {screw }}
$$
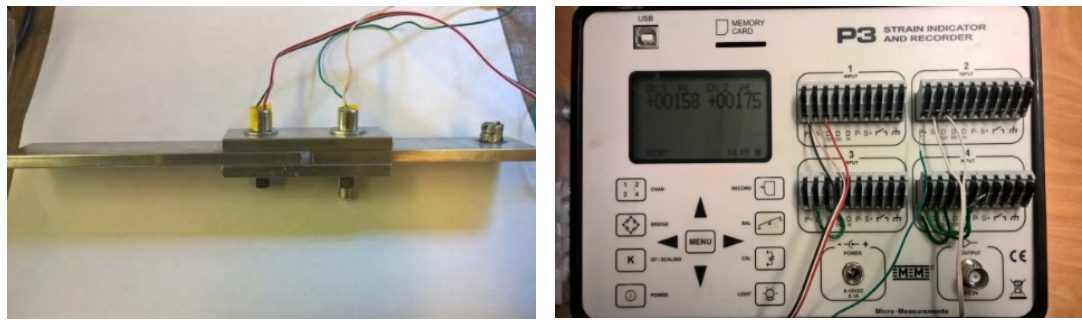

FIGURE 6. Specimen and strain gauge.

By the above formula and changing the value of strain gauge, the different preloads can be got (Table 2).

\begin{tabular}{|c|c|c|c|c|c|c|c|}
\hline & \multicolumn{3}{|c|}{ Preload (N) } & \multicolumn{2}{|c|}{ Stress (MPa) } & \multicolumn{2}{|c|}{ Strain (E-6) } \\
\hline $\begin{array}{l}\text { Num } \\
\text { ber }\end{array}$ & $\begin{array}{l}\text { Avera } \\
\text { ge }\end{array}$ & Screw 1 & Screw 2 & Screw 1 & Screw 2 & $\begin{array}{c}\text { Screw } \\
1\end{array}$ & $\begin{array}{c}\text { Screw } \\
2\end{array}$ \\
\hline 1 & $058^{557.3}$ & $69^{555.6}$ & 558.9427 & $14^{11.9}$ & $\begin{array}{lr}12.43 \\
2\end{array}$ & 16 & 16 \\
\hline 2 & $226^{1045 .}$ & $762^{1045 .}$ & 1044.691 & $22^{22.4}$ & 23.23 & 30 & 31 \\
\hline 3 & $878^{1595 .}$ & 431 & 1590.325 & $36^{34.3}$ & 35.37 & 46 & 47 \\
\hline 4 & 543 & $97{ }^{2094 .}$ & 2056.111 & $18^{44.9}$ & 45.73 & 60 & 61 \\
\hline 5 & $2488^{2600 .}$ & 423 & 2605.072 & $48^{55.6}$ & 57.94 & 75 & 78 \\
\hline 6 & $53 \quad 3115$. & $932 \quad 3126$. & 3104.128 & $44^{67.0}$ & 69.04 & 90 & 93 \\
\hline 7 & $262^{3647 .}$ & $088^{3648 .}$ & 3646.436 & $18^{78.2}$ & $\begin{array}{rr} & 81.10 \\
4\end{array}$ & $57^{10}$ & $96^{10}$ \\
\hline
\end{tabular}

TABLE 2. Strain and preload.

The specimen is fixed at one end, on the other end, a magnet is glued. The coil allows us to 
impose the exciting force on the magnet (Fig. 7).
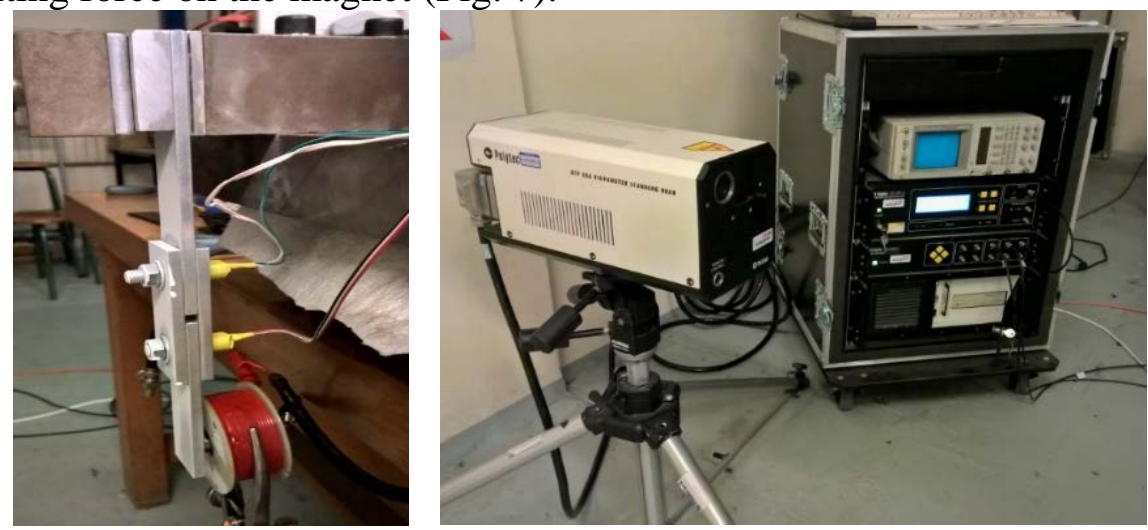

FIGURE 7. Vibrating portion and experimental equipment.

Vibration test instrument is Polytec Scanning Vibrometer PSV-300, which comprises an optical scanning head incorporating the laser interferometer sensor, beam steering optics and a video camera. Data from the scanning head are processed by the OFV-3001 vibrometer controller. A Windows NT workstation is responsible for scan point definition, data acquisition and control of the entire system. After select the frequency bands and presentation of data, we can export the graphical results with different preloads (Fig. 8 and Table 3).

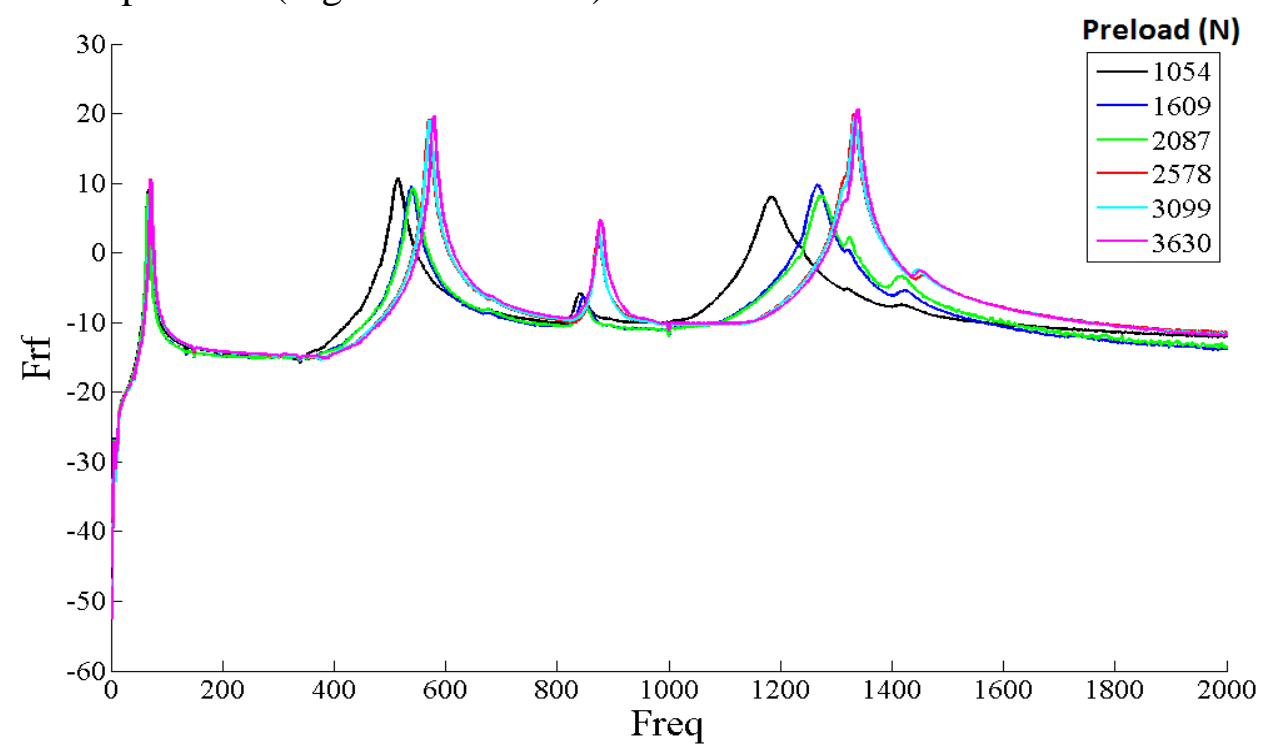

FIGURE 8. Frequency diagram.

TABLE 3. First three eigenfrequency with different preloads.

\begin{tabular}{|c|c|c|c|c|}
\hline & & \multicolumn{3}{|c|}{ Eigenfrequency $(\mathrm{Hz})$} \\
\hline Number & $\begin{array}{l}\text { Preload } \\
\text { (N) }\end{array}$ & $\begin{array}{l}\text { Firs } \\
t\end{array}$ & $\begin{array}{l}\text { Secon } \\
\text { d }\end{array}$ & $\begin{array}{l}\text { Thir } \\
\text { d }\end{array}$ \\
\hline 1 & 1053.79 & 67.5 & 513.8 & 1184 \\
\hline 2 & 1609.25 & 67.5 & 536.3 & 1268 \\
\hline 3 & 2087.25 & $\begin{array}{ll} & 66.2 \\
5 & \\
\end{array}$ & 541.3 & 1271 \\
\hline 4 & 2578.06 & $5^{71.2}$ & 570.0 & 1333 \\
\hline 5 & 3099.07 & $\begin{array}{ll} & 71.2 \\
5 & \end{array}$ & 571.3 & 1334 \\
\hline 6 & 3629.88 & $\begin{array}{ll} & 71.2 \\
5 & \end{array}$ & 577.5 & 1339 \\
\hline
\end{tabular}

From the frequency diagram, we can summarize that the eigenfrequency increase with the preload. The first eigenfrequency changes slightly and the growth rate is $3.7 \%$, the second eigenfrequency changes significantly and the growth rate is $9.64 \%$. Compared with the CATIA 
simulation, experimental data are close to the theoretical values. For the aluminum bolt, when the preload is more than $2000 \mathrm{~N}$, the eigenfrequency increase rapidly. Besides, it can find a special frequency between the second and third frequency. Mainly due to the fixed end can't be completely clamped and magnet position is not exactly on the center line.

\section{Steel bolt experiment}

In this experiment, the material and length of bolt are changed. Steel bolt as the picture shows (Fig. 9). Gauge length is $3 \mathrm{~mm}$, gauge resist is $120 \pm 0.3 \Omega$ and gauge factor is 2.06 and a hole is bored at the head of the bolt. The diameter of the bolt is still $8 \mathrm{~mm}$. Another way is used to fix the end of specimen and change the fixed form of electromagnetic coil.
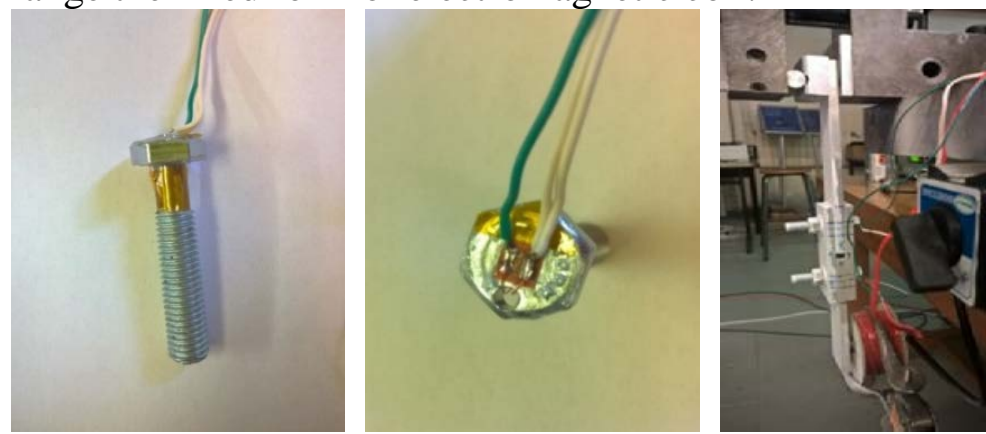

FIGURE 9. Steel bolt with strain gauge and fixed form.

With the measuring of Polytec Scanning Vibrometer, the graphical results (Fig. 10) and the eigenfrequency with different preloads (Table 4) are obtained.

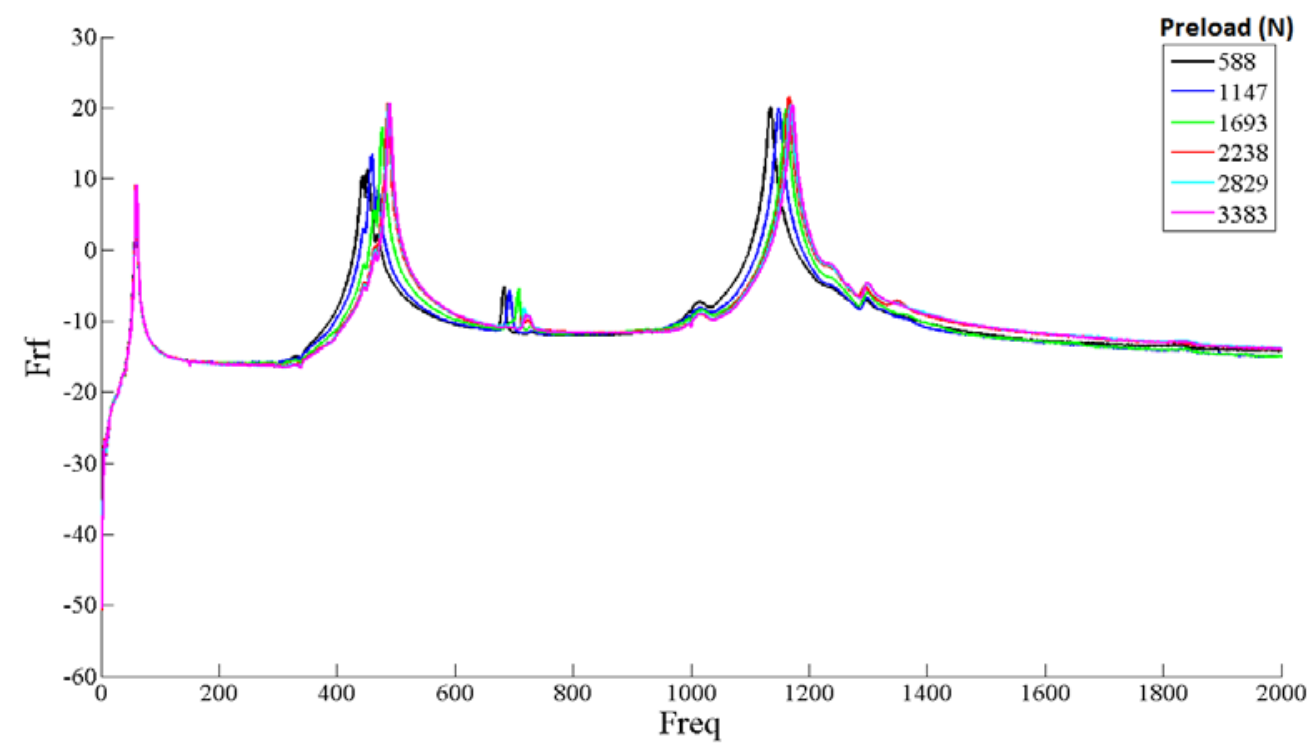

FIGURE 10. Frequency diagram. 
TABLE 4. First three eigenfrequency with different preloads.

\begin{tabular}{|c|c|c|c|c|}
\hline & & Eige & frequency & $\mathrm{Hz})$ \\
\hline er & $\begin{array}{l}\text { Preload } \\
\text { (N) }\end{array}$ & $t^{\text {Firs }}$ & nd & rd ${ }^{\text {Thi }}$ \\
\hline 1 & 587,81 & $\begin{array}{ll}58,7 \\
5\end{array}$ & 451,3 & $\begin{array}{ll} & 113 \\
5\end{array}$ \\
\hline 2 & 1147,36 & $5^{58,7}$ & 458,8 & $\begin{array}{ll} & 114 \\
8 & \end{array}$ \\
\hline 3 & 1692,77 & $5^{58,7}$ & 476,3 & $1^{116}$ \\
\hline 4 & 2238,19 & $5^{58,7}$ & 486,3 & $6^{116}$ \\
\hline 5 & 2828,83 & 60 & 487,5 & $\begin{array}{lr} & 116 \\
9 & \\
\end{array}$ \\
\hline 6 & 3382,72 & 60 & 488,8 & $1^{117}$ \\
\hline \multicolumn{2}{|c|}{ Growth rate } & $\%$ & $\% \quad \begin{array}{l}8.31 \\
\%\end{array}$ & $\%{ }^{3.17}$ \\
\hline
\end{tabular}

By the MATLAB, the every eigenshape with different preloads are compared (Fig. 11).

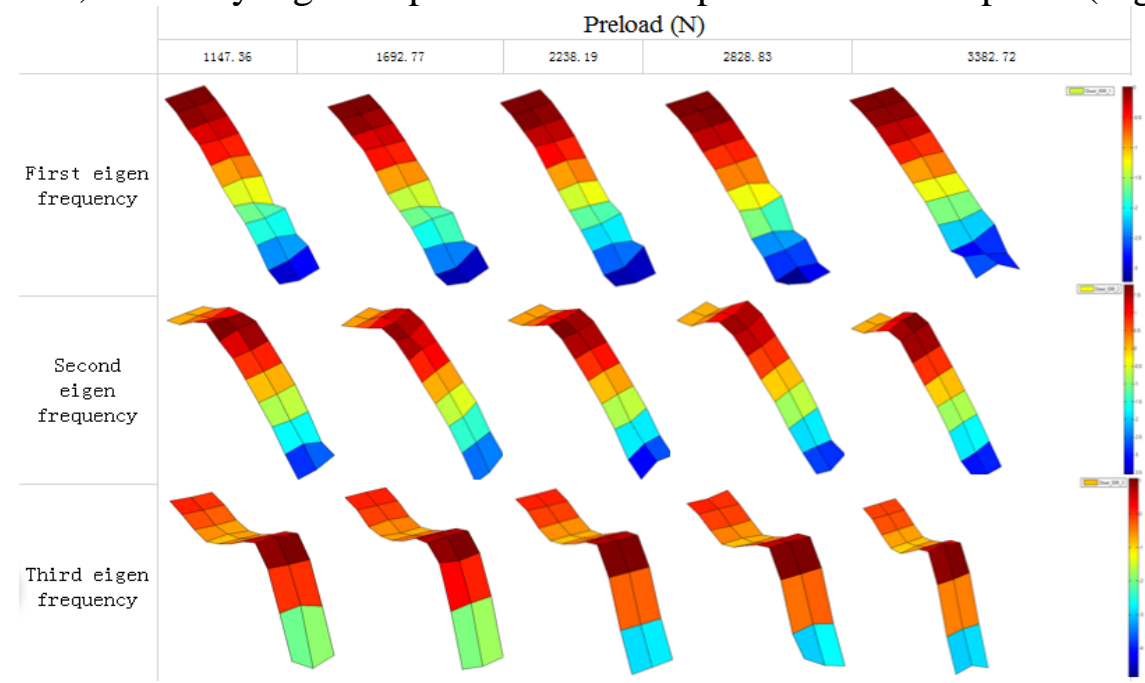

FIGURE 11. Eigenshape summary graph.

In order to be more sensitive to large differences and relatively insensitive to small differences in the mode shapes, the original Modal Assurance Criterion (MAC) is used. The MAC considers only modal shapes which mean that a separate frequency comparison must be used in conjunction with the MAC values to determine the correlated mode pairs. It is bounded between 0 and 1 , with 1 indicating fully consistent mode shapes. A value near 0 indicates that the modes are not consistent. The basic formula is as follow:

$$
\text { MAC }_{i j}=\frac{\left|\varphi_{i}^{\mathrm{t}} \varphi_{\mathrm{j}}\right|^{2}}{\left(\varphi_{\mathrm{i}}^{\mathrm{t}} \varphi_{\mathrm{i}}\right)\left(\varphi_{\mathrm{j}}^{\mathrm{t}} \varphi_{\mathrm{j}}\right)}
$$

Five experiments are conducted and each of the two modes are compared. The color plot is utilized to present magnitude data (Fig. 12) with MATLAB.
$\begin{aligned} \mathrm{Mac}_{\exp 1 \& 2} & =\left[\begin{array}{lll}0.99 & 0.38 & 0.37 \\ 0.38 & 0.99 & 0.42 \\ 0.37 & 0.38 & 0.99\end{array}\right] \mathrm{Mac}_{\exp 1 \& 3}=\left[\begin{array}{l}0.99 \\ 0.43 \\ 0.45\end{array}\right. \\ \mathrm{Mac}_{\exp 1 \& 5} & =\left[\begin{array}{lll}0.98 & 0.40 & 0.36 \\ 0.40 & 0.99 & 0.39 \\ 0.44 & 0.45 & 0.98\end{array}\right] \mathrm{Mac}_{\exp 2 \& 3}=\left[\begin{array}{l}0.99 \\ 0.39 \\ 0.36\end{array}\right.\end{aligned}$
0.40
0.99
0.45
0.377
0.40
0.33
$0.99 \quad 0.40$
$0.43 \quad 0.44$
0.98
$\begin{array}{ll}0.44 & 0.97\end{array}$
$\begin{array}{ll}0.42 & 0.43\end{array}$
0.98
$[0.98$
0.99
0.47
$\begin{array}{ll}0.38 & 0.97\end{array}$
0.38
0.95 


$$
\begin{aligned}
\operatorname{Mac}_{\text {exp2\&5 }}=\left[\begin{array}{lll}
0.98 & 0.40 & 0.43 \\
0.39 & 0.99 & 0.48 \\
0.35 & 0.38 & 0.96
\end{array}\right] \operatorname{Mac}_{\exp 3 \& 4} & =\left[\begin{array}{lll}
0.99 & 0.43 & 0.43 \\
0.44 & 0.99 & 0.45 \\
0.40 & 0.46 & 0.99
\end{array}\right] \mathrm{Mac}_{\exp 3 \& 5}=\left[\begin{array}{lll}
0.99 & 0.41 & 0.43 \\
0.44 & 0.99 & 0.46 \\
0.43 & 0.45 & 0.99
\end{array}\right] \\
\mathrm{Mac}_{\text {exp } 4 \& 5} & =\left[\begin{array}{lll}
0.99 & 0.41 & 0.39 \\
0.43 & 0.99 & 0.46 \\
0.42 & 0.44 & 0.99
\end{array}\right]
\end{aligned}
$$

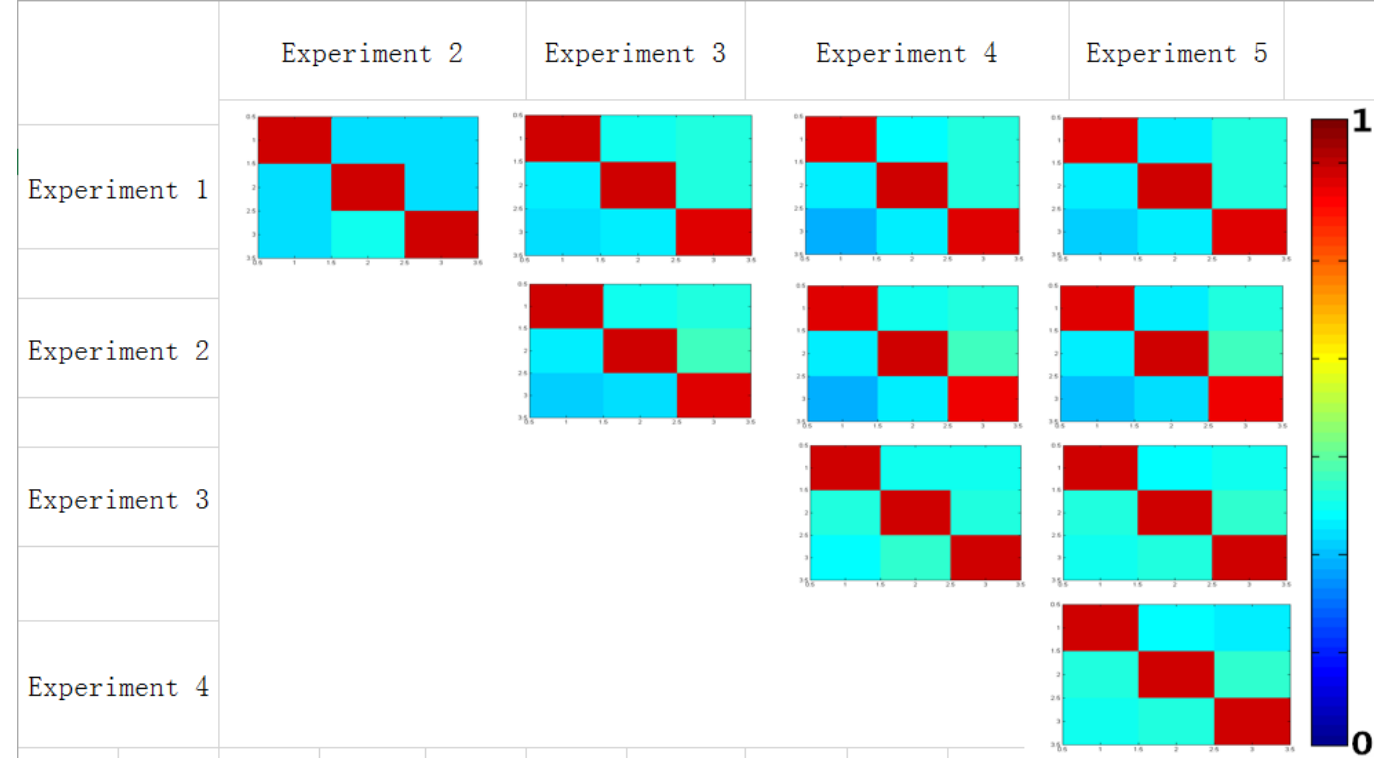

FIGURE 12. 2-D presentation of MAC values.

\section{CONCLUSION}

This article is mainly divided into two parts. In the first part, we analyzed the eigenfrequency of a simple single beam with different size parameters. In the second part, two different experiments are conducted. The first one is aluminum bolt and the second is steel bolt.

- The eigenfrequency exhibits a linear shape increase with the increase of the parameter. It is summarized that the thickness of beam makes the maximum impact on the model's eigenfrequency and the diameter of bolt makes the minimal impact factor.

- From the frequency diagram, it is summarized that the eigenfrequency increase with the preload. Compared these three experiments, the eigenfrequency of aluminum bolt is bigger than steel bolt and the eigenfrequency of steel bolt is bigger than the steel bolt with measured cylinder at the same preload.

- For the two different types of bolted joints, the first eigenfrequency has the smallest change, the second eigenfrequency changes most significantly and the growth rate is about $9.4 \%$.

- By comparison software simulation and experimental results, the eigenshapes of the first three flexural vibrations are very similar and the vibration trend is the same. By means of the MAC, the main diagonal values are approximately 1 and values of the rest position are approximately 0.4. So these modes of different preloads' experiments are not consistent.

The test bench will allow us to obtain numerical and experimental analysis; it can be used for characterizing uncertainties in bolted joints. Moreover, it is possible to study the vibration of bolted joints when the boundary conditions are all free. Besides, the quasi-static analysis will be made and the friction between surfaces should be analyzed.

\section{ACKNOWLEDGMENTS}

The research presented in this paper was supported by National Natural Science Foundation of China (51575010), Key technology innovation ability platform of Heavy NC machine tool (2013ZX04013011), and Study on micro macro contact mechanism and mechanical behavior of high strength bolted joint of heavy machine tool (51375025). 


\section{REFERENCES}

[1] Ibrahim, R.A., PettitC.L, Uncertainties and dynamic problems of bolted joints and other fasteners, Journal of Sound and Vibration, Volume 279, Issues 3-5, 21 January 2005, pp. 857936.

[2] E.E.Ungar, The status of engineering knowledge concerning the damping of built-up structures, Journal of Sound and Vibration, Volume 26, Issue 1, 1973, pp. 141-154, ISSN 0022-460X.

[3] T. Dang Hoang, C. Herbelot, A. Imad, On failure mode analysis in a bolted single lap joint under tension-shearing, France, 2012.

[4] Y. Song, C.J. Hartwigsen, D.M. McFarlanda, Simulation of dynamics of beam structures with bolted joints using adjusted Iwan beam elements, MC-236, Urbana, IL 61801, USA, 2003.

[5] J.L. Dohner, White paper: on the development of methodologies for constructing predictive models of structures with joints and interfaces, Sandia National Laboratories SAND2001-0003P, 2001.

[6] J.W. Fisher, J.H.A. Struik, Guide to Design Criteria for Bolted and Riveted Joints, Wiley, New York, 1974.

[7] J.H. Bickford, The bolting technology council and the search for more accurate preload, ASME Pressure Vessels and Piping Conference on Advances in Bolted Joint Technology, PVP-Vol. 158, 1989, pp. 1-6.

[8] J.H. Bickford, J.H., An Introduction to the Design and Behavior of Bolted Joints, 2nd Edition, Marcel Dekker Inc., New York, 1990.

[9] B.D. Agarwal, L.J. Broutman, Analysis and Performance of Fiber Composites, Wiley, New York, 1990.

[10] Kuanmin Mao, BinLi, JunWu, XinyuShao, Stiffness influential factors-based dynamic modeling and its parameter identification method of fixed joints in machine tools, PRChina, 2009.

[11] Yongsheng Zhao, Cheng Yang, Surface contact stress-based nonlinear virtual material method for dynamic analysis of bolted joint of machine tool, Beijing 100124, PR China, 2015. 